\title{
Predictors of binge eating: relevance of BMI, emotional eating and sensivity to environmental food cues
}

\author{
Maša Černelič-Bizjak \\ Department of Nutritional Counseling - Dietetics, Faculty of Health Sciences, \\ University of Primorska, Izola, Slovenia, and \\ Raquel P.F. Guiné \\ CI\&DETS and CERNAS Research Centres, Polytechnic Institute of Viseu, \\ Viseu, Portugal
}

Predictors of binge eating

\begin{abstract}
Purpose - Understanding humans' food intake practices is helpful in reducing health problems. The purpose of this study was to investigate the relationships between eating behaviours and binge eating and to examine the influence of sex and weight status on these relationships.

Design/methodology/approach - A total of seventy-eight participants (39 with overweight; mean age: $38.1 \pm 6.3$ years; body mass index [BMI]: $25 \pm 5.7 \mathrm{~kg} / \mathrm{m}^{2}$ ) underwent measurements of binge eating, eating styles and body compositions. A hierarchical multiple regression analysis was performed to predict binge eating as a function of eating styles and demographic variables.

Findings - Women presented higher levels of binge eating symptomatology and emotional eating than men. The analysis showed that age and gender did not emerge as important predictors of binge eating. In contrast, emotional and external eating and BMI were found to be important predictors of binge eating. The results indicate that higher emotional and external eating behaviour with higher BMI are important risk factors for binge eating in a non-clinical sample.

Originality/value - In this study, BMI was used as a causal factor rather than a consequence of deregulation of eating behaviour. An individual's tendency to binge eat may be determined by BMI, emotional eating and sensitivity to environmental food stimuli. Understanding sex differences and causal relationships between eating behaviours is critical for the prevention and treatment of obesity and related health problems and for proper dietary management.
\end{abstract}

Keywords Eating behaviour, Emotional eating, External eating, Binge eating, Eating pattern, Overeating Paper type Research paper

(C) Maša Černelič-Bizjak and Raquel P.F. Guiné. Published by Emerald Publishing Limited. This article is published under the Creative Commons Attribution (CC BY 4.0) licence. Anyone may reproduce, distribute, translate and create derivative works of this article (for both commercial and non-commercial purposes), subject to full attribution to the original publication and authors. The full terms of this licence may be seen at http://creativecommons.org/licences/by/4.0/legalcode

Declaration of competing interests: The authors declare no conflict of interest.

Funding: This research did not receive any specific grant from funding agencies in the public, commercial, or not-for-profit sectors.

CRediT authorship contribution statement: MČB designed the study and conducted the data collection. MČB and RQ conducted statistical analysis, the interpretation of the results, participated in drafting the publication and approved the final version of the publication.

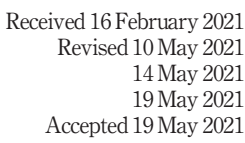

Accepted 19 May 2021

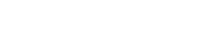


NFS

52,1

\section{Introduction}

Human behaviours related to food intake, which influence the frequency of eating, meal size, meal content and attitude to meals, are described as "eating behaviours." Food intake and eating behaviour are the result of numerous complex regulatory mechanisms, including both homeostatic and hedonic/non-homeostatic processes and can manifest as eating in the absence of energy or metabolic deficits (Liu and Kanoski, 2018). Individual differences in eating behaviour should at least partly explain individual differences in obesity (Vainik et al., 2019). Many eating-related constructs have been proposed to explain obesity, such as emotional eating and binge eating, both of which emphasize loss of control over food intake. Nevertheless, the indicators for these two constructs of uncontrolled eating are quite different.

The concept of emotional eating refers to the tendency to eat in response to emotional triggers as opposed to a true physiological need for food, such as negative emotions or stress (Bongers and Jansen, 2016) and positive emotions (Cardi et al., 2015). Moreover, emotional eating tends to co-occur with overeating in response to food-related cues such as the sight and smell of attractive food (Van Strien, 2018), where emotional eaters shift their attention away from their affect by narrowing it to the immediate (food) environment with the resulting external eating. In fact, emotional eaters as compared to non-emotional eaters report greater consumption of high fat and sweet snacks (Camilleri et al., 2007). Importantly, emotional eating is associated with increased body mass index (BMI), greater waist circumference, more body fat and abdominal obesity (Péneau et al., 2013; Bourdier et al., 2018; Konttinen et al., 2019; Nightingale and Cassin, 2019) and may be an explanatory factor of the weight regain of many dieters (Van Strien, 2018). Thus, emotional eating is one factor that may be related to overeating (Frayn and Knäuper, 2018), and to binge eating, that is characterized as the consumption of an unusually large amount of food over a short period of time coupled with feelings of loss of control during the eating episode [American Psychiatric Association (APA), 2013]. Importantly, emotional eating and binge eating are distinct constructs. In that, emotional antecedents are neither required to trigger overeating such as binge eating (APA, 2013) nor is eating an unusually large amount of food over a short period of time required for emotional eating. Moreover, binge eating has marked feelings of loss of control during the eating episode (APA, 2013), a clinical feature unshared by emotional eating. That said, emotional eating and binge eating share negative consequences such as weight gain over time or possible development of obesity (Udo and Grilo, 2018).

As obesity has reached epidemic proportions (WHO, 2020) and the evidence that emotional eating is a possible motivator or mediator between obesity, disordered eating and various health problems suggests that reducing emotional eating could be an important treatment goal for both obesity and its health consequences. In a recent study, Vainik and colleagues (Vainik et al., 2019) reviewed cross-sectional and longitudinal data and showed that uncontrolled eating, including emotional and binge eating, is phenotypically and genetically related to BMI and food intake. The authors' concluding remarks are that uncontrolled eating and BMI tend to be separable phenomena that influence each other. Thus, there is great potential in the design of studies to understand the dynamics between this uncontrolled eating, food intake and BMI. Although it is clear that eating behaviours and BMI are closely linked across the life span (French et al., 2012), there is no conclusive facts about the relationship between problematic eating behaviours and body weight.

The main aim of the study was to investigate the relations between uncontrolled eating behaviours, demographic and anthropometric variables. The objective was to test differences between normal weight and overweight asymptomatic adults for uncontrolled eating and explored the associations of demographic variables, BMI and emotional/external eating to overeating practice. As high BMI is most often the result of an excessive intake of calories in relation to energy expenditure (Hill et al., 2013), the link with overeating seems 
obvious. In this study, we hypothesized that BMI is a causal factor and no longer a consequence of a deregulation of eating behaviour and that higher BMI can also lead to higher uncontrolled eating.

\section{Materials and methods}

Study design and participants

Participants from the general population who met the inclusion criteria and passed the baseline physical examination were included in the cross-sectional study. The exclusion criteria were the presence of cardiovascular, endocrine, acute or chronic inflammatory diseases, taking medication for lipid metabolism or psychiatric disorders and unstable weight in the last threemonths, BMI $<30 \mathrm{~kg} / \mathrm{m}^{2}$. A physician confirmed the health conditions of the participants through a complete review of medical history and physical examination. Of the 182 volunteers screened for eligibility, 86 participants did not meet the criteria for inclusion in the study and were excluded. After this exclusion of participants, we calculated (a priori) the minimum required sample size for a multiple regression study, taking into account the desired probability level, the number of predictors in the model, the anticipated effect size and the desired statistical power level. With an anticipated effect size $\left(f^{2}\right)$ of 0.35 , a desired statistical power level of 0.8 , a number of predictors of 6 and probability level of 0.05 , the calculated minimum sample size was 46 . Of 124 eligible participants, 18 participants did not complete all questionnaires, and 78 adults, aged between 25 and 49 years ( $38.1 \pm 6.3$ years; 23 women), completed the study.

All the participants gave their informed consent prior to their inclusion in the study. The study protocol and the potential risk of the study were fully explained to the participants before they provided written informed consent. The protocol was designed at the Department of Nutritional Counselling and Dietetics of the Faculty of Health Sciences and approved by the institution's Ethics Committee.

\section{Eating behaviour assessment}

Eating behaviour was assessed with the Dutch Eating Behaviour Questionnaire (DEBQ) (Van Strien et al., 1986). The DEBQ consists of 33 items, 13 on emotional eating (e.g. "Do you have a desire to eat when you are irritated?"), 10 on external eating (e.g. "If food smells and looks good, do you eat more than usual?") and 10 on restrained eating (e.g. "Do you try to eat less at mealtimes than you would like to eat?"). All items were rated on a five-point scale with response categories ranging from 1 "never" to 5 "very often." The three scales are based on different aspects of eating behaviour and provide insight into the structure of eating behaviour and the different causes of potential overeating. The questionnaire was translated into the Slovene language, and back translated, for research purposes before we obtained permission from the publisher to use it (Boom Test Publishers, Amsterdam). In this sample, the calculated alpha coefficients ranged from 0.92 to 0.94 for the restrained eating subscale, 0.96 to 0.97 for the emotional eating subscale and 0.79 to 0.84 for the external eating subscale.

\section{Binge eating behaviour assessment}

Tendencies to overeat were evaluated by asking participants to indicate how many out of the last seven days they had "rapidly consumed an excessive amount of food." Participants were asked to rate ten items and indicate whether the description of the behaviour and feelings related to their dietary situations/habits was "true" or "not true." The items were developed on the basis of the definition found in the Diagnostic and Statistical Manual of Mental Disorders (APA, 2013) of binge eating (i.e. binge episodes associated with loss of
Predictors of binge eating 
control) and the use of literature in this field (Mason and Lewis, 2014). Item examples included: "I can eat many different foods at once," "I cannot control myself, I feel extreme hunger," "I swallow food, I eat very fast and do not even notice how much I eat," "I eat until I feel I have overeaten," "I eat even though I am not hungry" and "I feel guilty after such a meal." The answers were rated 0 or 1 ( 0 - not true, 1 - true). As a result, their cumulative answers could range from 0 to 10 . Higher scores mean a (more frequent) occurrence of features/symptomatology associated with episodes of binge eating. In this sample, the calculated alpha coefficient was 0.90 .

\section{Anthropometric measurements}

Body weight, height and BMI: Body height was measured with a Leicester height measure at $0.1 \mathrm{~cm}$ accurate, in a standing position, without shoes. Body weight was measured in light clothing and with no shoes using a digital scale with an accuracy of $0.1 \mathrm{~kg}$. BMI was calculated using a standard formula: BMI = body weight $(\mathrm{kg}) /$ height $\left(\mathrm{m}^{2}\right)$.

\section{Procedure}

The purpose of the study and its procedures were fully explained to all participants, and an informed written consent was obtained from each participant. Ethical considerations, including anonymity, confidentiality and voluntary participation, were considered in accordance with the American Psychological Association's Ethical Principles in accordance with the Helsinki-Tokyo Declaration (Carlson et al., 2004). All measurements used in the study were individually conducted at the Faculty of Health Sciences by a trained psychologist and nutritionist.

\section{Data analysis}

The data were analysed with the IBM SPSS Statistics 24 for Windows. All variables were tested for normal distribution (Kolmogirov-Smirnov test and Shapiro-Wilk test). In addition to descriptive statistics, Cronbach's alphas were calculated to assess the internal consistency of the measurement instruments. Mann-Whitney U test was used to investigate differences between BMI groups according to eating behaviours. Spearman's correlation analyses were performed to examine the associations between eating behaviour styles, BMI and binge tendencies. Statistical significance was set at $p<0.05$. Furthermore, hierarchical multiple regression was used to determine the extent to which the studied variables could be viewed as predictors of binge eating.

\section{Results}

\section{General characteristics of the sample and eating-related styles}

The final analytic sample included 78 participants aged between 25 and 49 years (mean $=38.1$ ), the majority of whom were female (67 \%). In total $10 \%$ of respondents were in a relationship, $35 \%$ were married and $20 \%$ were single. Almost half (i.e. $42 \%$ ) of the participants lived in a household with four persons, a quarter (25\%) in a household with two persons, $8 \%$ cohabitated with more than five persons and $10 \%$ lived alone. Descriptive statistics for the whole sample (mean, standard deviation, skewness and kurtosis values) are presented in Table 1. Although the mean values for the DEBQ subscales were slightly above average, considerable variability was observed, particularly in external and restrained eating subscales. Both the KolmogorovSmirnov and Shapiro-Wilk tests were used to verify the normality assumption. The results revealed that some of the data did not follow normal distribution; therefore, non-parametric statistics were performed during further analyses. 
The mean BMI (weight in kilograms/length in metres raised to the square) was 25.0 and ranged from 19.1 to 30.0 representing a wide range of lean to overweight subjects. According to the anthropometric parameters, they were grouped into normal weight and overweight group. Overweight and obesity were defined as BMI $25-29$ and $\geq 30 \mathrm{~kg} / \mathrm{m}^{2}$, respectively, by large waist circumference $(\geq 94 \mathrm{~cm}$ in men and $80 \mathrm{~cm}$ in women) and by high $\%$ of total fat ( $\geq 21.5 \%$ in men and $\geq 32 \%$ in women) (data not shown). Participants with at least two of these characteristics were classified as member of the overweight group which finally consisted of 39 overweight members, 13 males and 26 females. The members of the normal weight group were selected with regards to the characteristics of the overweight group members so that both groups were equivalent in terms of relevant factors (i.e. gender, age, health state). The final sample of control group consisted of 39 normal weight members, 13 males and 26 females.

\section{Differences in eating - related styles and binge eating}

Differences in DEBQ subscales between the BMI groups and gender are presented in Table 2. In the normal weight group, the mean BMI was: $22.9 \pm 2.3$ for men and $20.8 \pm 2.3$ for women; in the overweight group: $28.9 \pm 2.9$ for men and $28.3 \pm 1.7$ for women (Table 2). Pairwise comparisons revealed that overweight participants scored higher on the emotional eating subscale than normal-weight participants $(\phi=0.01)$. No significant differences were observed in external and restrained eating/restriction among the two BMI categories. There were gender differences found in emotional eating - with overweight women reporting more emotional eating behaviours $\phi=$ 0.01 ) than normal-weight women. When we compared normal-weight and overweight men, we found no statistically significant differences $(\phi=0.05)$ in eating behaviours.

Furthermore, the Mann-Whitney test showed that normal-weight participants scored lower than overweight participants on the binge eating scale $(\phi=0.00)$. It should be noted that a higher value on the above scale means a more (frequent) occurrence of tendencies to overeat associated with episodes of binge eating. Gender differences were found for binge eating with overweight women reporting more binge eating tendencies $(\phi=0.00)$ than normal-weight women. Overweight men reported more binge eating tendencies than normal-weight men $\operatorname{did}(\phi=0.00)$.

\section{Predicting binge eating: relations to eating-related styles, age and body mass index}

The aim of the study was to explore the possible relationship between the binge eating and eating styles, e.g. emotional, external and restrained eating behaviour, and BMI. Spearman's correlation analysis revealed that binge eating was significantly correlated with emotional

\begin{tabular}{lllc}
\hline & Min & Max & Mean \pm SD \\
\hline Age (years) & 25 & 49 & $38.1 \pm 6.3$ \\
BMI (kg/m $\left.{ }^{2}\right)$ & 19.1 & 30.9 & $25 \pm 5.9$ \\
Body fat $(\%)$ & 10 & 42 & $27 \pm 5$ \\
$D E B Q^{a}$ & & & \\
Emotional eating & 1.0 & 4.5 & $1.8 \pm 0.9$ \\
External eating & 1.8 & 4.8 & $2.9 \pm 0.6$ \\
Restrained eating & 1.2 & 4.3 & $2.6 \pm 0.6$ \\
Binge eating & 0.0 & 10.0 & $1.9 \pm 3.5$
\end{tabular}

Notes: ${ }^{\mathrm{a}} \mathrm{DEBQ}=$ Dutch Eating Behaviour Questionnaire. Descriptive statistics for the eating behaviour variables are presented as mean $\pm \mathrm{SD}$
Predictors of binge eating

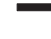




\begin{tabular}{|c|c|c|c|c|c|}
\hline \multirow{3}{*}{$\begin{array}{l}\text { NFS } \\
52,1\end{array}$} & & & & & \\
\hline & & \multirow{2}{*}{$\begin{array}{c}\text { Normal weight } \\
n\end{array}$} & \multirow{2}{*}{$\begin{array}{l}\text { Overweight } \\
\text { Mean } \pm \text { SD }\end{array}$} & \multicolumn{2}{|c|}{$\begin{array}{c}\text { Differences } \\
\text { between groups }\end{array}$} \\
\hline & & & & Mean \pm SD & $P$-value \\
\hline \multirow{4}{*}{176} & BMI $\left(\mathrm{kg} / \mathrm{m}^{2}\right)$ & 78 & $21.4 \pm 2.3$ & $28.6 \pm 2.3$ & $<0.01$ \\
\hline & Men & 26 & $22.9 \pm 2.3$ & $28.9 \pm 2.9$ & $<0.01$ \\
\hline & Women & 52 & $20.9 \pm 2.6$ & $28.3 \pm 1.7$ & $<0.01$ \\
\hline & Body fat (\%) & 78 & $21 \pm 5$ & $33 \pm 6$ & $<0.01$ \\
\hline & Men & 26 & $15 \pm 5$ & $25 \pm 3$ & $<0.01$ \\
\hline & Women & 52 & $24 \pm 5$ & $39 \pm 4$ & $<0.01$ \\
\hline & Emotional eating & 78 & $1.6 \pm 0.9$ & $2.2 \pm 0.8$ & $<0.05$ \\
\hline & Men & 26 & $1.5 \pm 0.4$ & $1.6 \pm 0.5$ & ns \\
\hline & Women & 52 & $1.7 \pm 0.8$ & $2.4 \pm 0.7$ & $<0.05$ \\
\hline & External eating & 78 & $2.9 \pm 0.6$ & $3.1 \pm 0.6$ & $\mathrm{~ns}$ \\
\hline & Men & 26 & $2.7 \pm 0.4$ & $2.9 \pm 0.5$ & ns \\
\hline & Women & 52 & $2.8 \pm 0.6$ & $3.0 \pm 0.6$ & ns \\
\hline & Restrained eating & 78 & $2.6 \pm 0.6$ & $2.5 \pm 0.5$ & ns \\
\hline & Men & 26 & $2.4 \pm 0.6$ & $2.5 \pm 0.2$ & ns \\
\hline Table 2. & Women & 52 & $2.6 \pm 0.6$ & $2.9 \pm 0.5$ & ns \\
\hline Differences in the & Binge eating & 78 & $0.5 \pm 1.6$ & $2.6 \pm 2.3$ & $<0.01$ \\
\hline DEBQ subscales and & Men & 26 & $0.2 \pm 0.8$ & $1.7 \pm 2.3$ & $<0.01$ \\
\hline binge eating between & Women & 52 & $0.6 \pm 1.8$ & $3.2 \pm 2.6$ & $<0.01$ \\
\hline
\end{tabular}
participants according to BMI and gender

Notes: All values are mean \pm SD. Comparisons of eating behaviour between the two groups (for males and females separately) were tested with Mann-Whitney U-test. $P$-value less than 0.05 was considered as statistically significant (ns, non-significant)

eating $(r=0.62, p=0.01)$, external eating $(r=0.45, p=0.01)$ and with BMI $(r=0.52, p=0.01)$ (Table 3). The tendency to overeat was not correlated with restrained eating, gender or age. Correlations between DEBQ subscale were: between emotional and external $r=0.52$, emotional and restrictive $r=0.23$, external and restrictive $r=0.19$.

A hierarchical multiple regression analysis with binge eating as the dependent variable was performed to examine the predictive validity of eating styles (e.g. emotional, external and restrained eating) and demographic variables (Table 3 ). These analyses revealed that at Step 1 , age and gender did not contribute significantly to the regression model $(\phi=0.05)$; however, these two variables accounted for $2 \%$ of the variation in binge eating, and only gender $(\beta=$ $0.18 ; p=0.050$ ) was an important predictor of binge eating. BMI was entered as a control variable in Step 2 of the model. Introducing BMI as an independent variable in Stage 2 of the regression model explained an additional $27 \%$ of the variation in binge eating, and BMI was a significant predictor of the tendencies to overeat. The addition of emotional eating as a predictor to the regression model at Step 3 revealed that emotional eating was a significant predictor of binge eating $(\beta=0.42, p=0.00)$ and accounted for an additional $13 \%$ of the variance in binge eating. In Step 4, external eating was added: it was a significant predictor of binge eating $(\beta=0.22 ; p=0.00)$, and it contributes significantly to the regression model and accounted for $3 \%$ of the variation in binge eating. In Step 5 , restrained eating was added, but it did not contribute significantly to the regression model. Overall, the final model explained $42 \%$ of the variation in binge eating ( $\operatorname{total} R^{2}=0.42 ; p=0.00$ ).

\section{Discussion}

We hypothesized that BMI is a causal factor and no longer a consequence of a deregulation of eating behaviour and that higher BMI can also lead to higher uncontrolled eating. In this 


\begin{tabular}{|c|c|c|c|c|c|c|}
\hline Predictor & \multicolumn{5}{|c|}{$\begin{array}{l}\text { Dependent variable } \\
\text { Binge eating }\end{array}$} & $\begin{array}{l}\text { Predictors of } \\
\text { binge eating }\end{array}$ \\
\hline \multirow{8}{*}{$\begin{array}{l}\text { Step 1 } \\
\text { Age (years) } \\
\text { Gender } \\
\text { Step 2 } \\
\text { BMI } \\
\text { Step 3 } \\
\text { Emotional eating } \\
\text { Step 4 } \\
\text { External eating } \\
\text { Step 5 } \\
\text { Restrained eating } \\
\text { Total } R^{2}\end{array}$} & & 0.02 & 0.13 & & & \\
\hline & 0.09 & & & 0.05 & ns & \\
\hline & 0.20 & & & $0.18^{*}$ & 0.05 & \\
\hline & $0.52 * *$ & 0.26 & 0.00 & $0.51 * * *$ & 001 & 177 \\
\hline & & 0.39 & 0.00 & & & \\
\hline & $0.62 * *$ & 0.42 & 000 & $0.42 * * *$ & $<0.01$ & \\
\hline & $0.45^{* *}$ & 0.42 & 0.00 & $0.22^{* * *}$ & $<0.05$ & \\
\hline & 0.21 & 0.42 & & -0.08 & ns & Table 3. \\
\hline $\begin{array}{l}\text { Notes: } n=78 ; * \mathrm{H} \\
\text { (stepwise). Linear } \\
\text { each subsequent st } \\
\text { the beta values in } \\
0.05 \text { was considere }\end{array}$ & $\begin{array}{l}1 \text { regress } \\
\text { n obtain } \\
\text { model, re } \\
\text { n are the } \\
\text { stically si }\end{array}$ & $\begin{array}{l}\text { jing th } \\
\text { earson } \\
\text { om the } \\
\text { d coeff } \\
\text { (ns, no }\end{array}$ & $\begin{array}{l}f \text { predi } \\
\text { ion tes } \\
\text { of a p } \\
\text { f the e } \\
\text { cant) }\end{array}$ & $\begin{array}{l}\text { les into the } \\
\text { = the change } \\
\text { he regressio } \\
\text { variables. }\end{array}$ & $\begin{array}{l}\text { n steps } \\
\text { lue for } \\
\text { on. } \beta= \\
\text { ss than }\end{array}$ & $\begin{array}{r}\text { Linear and } \\
\text { hierarchical multiple } \\
\text { regression analysis } \\
\text { predicting binge } \\
\text { eating* }\end{array}$ \\
\hline
\end{tabular}

study, binge eating behaviour was associated with higher BMI, and significant associations were found between emotional eating and BMI. Additionally, according to the results of the regression analysis, BMI and emotional/external eating had significant positive effects on binge eating behaviour. Thus, participants with a higher BMI who reported more emotional eating were more involved in binge eating and had more pronounced tendencies to overeat. Our findings support the hypothesis of the study that a higher BMI indeed could present a causal risk factor for uncontrolled eating behaviour and no longer a consequence of a deregulation of eating behaviour likely in a non-clinical sample.

This association found in the present study between uncontrolled eating and BMI is consistent with previous investigations, where the studies suggest a more complex picture, with changes in body weight also affecting eating behaviours (Boggiano et al., 2015). Additionally, based on some longitudinal findings summarized in the paper of Vainick et al. (2019), uncontrolled eating can lead to higher BMI, but higher BMI can also lead to higher uncontrolled eating. A possible interpretation is that uncontrolled eating and BMI share a set of genes, which cause both variation in BMI and variation in uncontrolled eating (Vainick et al., 2019).

Regarding eating behaviour in relation to weight in this study, a significant difference between normal weight and overweight participants was found only in emotional eating. Few studies have examined emotional eating and body weight over time (Hays and Roberts, 2008) and showed that emotional eating was an important correlation of later body weight and BMI. Although this study is limited to the characteristics of the sample (i.e. including only older women), the results provide evidence that emotional eating can influence later body weight and the development of obesity and appears to be an important factor related to body weight over time.

Furthermore, females with overweight reported higher emotional eating and dietary restrictions (i.e. restricted food intake) compared to overweight men. This finding is in line with the reports of studies which emphasise the importance of demographic factors, especially gender (Yu et al., 2018), in the development of eating styles. Overall, some studies 
NFS

52,1

show that the influence of stress and eating styles on food intake and obesity is stronger in women than in men (e.g. Lluch et al., 2000; O'Connor et al., 2008).

In this study, binge eating behaviour was positively correlated with emotional and external eating, which was found to be in agreement with some previous studies (Pinaquy et al., 2003; Schulz and Laessle, 2010; Stice et al., 2002). Cross-sectional study (Scherwitz and Kesten, 2005) showed that emotional eating is a factor which is positively associated with the self-estimated frequency of binge eating. In addition, the participants with overweight differed from normal weight of the same age in that they reported a higher frequency of binge eating and a higher level of emotional eating. Results reported by some studies show that women have a significantly higher prevalence of overeating and also overeating-related eating disorders than men (Treasure et al., 2010). Regarding the effects of sex on food cravings, Imperatori and colleagues found that females with overweight or obesity were more likely to experience cravings than males (Imperatori et al., 2013), and Chao and colleagues highlight that females had significantly higher cravings for sweets than males (Chao et al., 2015). However, it is not known whether different psychological factors related to eating have a similar relationship with eating behaviours and obesity indicators in both gender, as most studies on the psychological aspects of eating have included only women. Because individuals who exhibit high levels of uncontrolled eating at baseline generally tend to gain weight over time (French et al., 2012), the detection of uncontrolled eating behaviours (such as emotional eating and binge eating) is essential not only for the prevention and treatment of excessive body weight but also of other medically related conditions, particularly in asymptomatic young populations. Teaching effective coping strategies along with nutrition education is particularly important in weight loss treatments which have repeatedly shown to be ineffective in reducing overeating based on behaviour alone (Iacovino et al., 2012), as they are unlikely to target eating styles. Therefore, it is perhaps important that professionals working with individuals with overweight and obesity record and evaluate eating behaviour and possibly other clinically relevant symptoms, such as depressive symptoms (Mason and Lewis, 2014), and adjust interventions according to these characteristics.

This study has some limitations. Being cross-sectional in nature, it does not allow for the detection of any causal relationship between the variables taken into account. Next, certain important data of this study were self-reported. In spite of the limitations, one of the strengths of the study is that weight and height were measured in each participant, which provides more accurate information than self-reported methods.

\section{Conclusions}

In the present study, BMI, emotional eating and external eating were found to be important predictors of binge eating in adult men and women. Importantly, in this nonclinical sample, BMI was a causal factor rather than a consequence of deregulation of eating behaviour. It appears that uncontrolled eating and BMI are somewhat separable phenomena mutually influencing each other. However, other factors contributing to uncontrolled eating and BMI should also be considered.

A holistic approach to obesity prevention and management should include the detection of both weight loss and reduction of uncontrolled eating, in addition to other risk factors for obesity. Adequate management of emotions, recognition of individuals prone to binge eating and nutrition education are critical in asymptomatic young and adults to reduce the high risk of obesity. 


\section{References}

American Psychiatric Association (2013), DSM-5: Diagnostic and Statistical Manual of Mental Disorders, 5th ed. Arlington, VA: American Psychiatric Publishing.

Boggiano, M.M., Wenger, L.E., Turan, B., Tatum, M.M., Morgan, P.R. and Sylvester, M.D. (2015), "Eating tasty food to cope. Longitudinal association with BMI", Appetite, Vol. 87, pp. 365-370.

Bongers, P. and Jansen, A. (2016), "Emotional eating is not what you think it is and emotional eating scales do not measure what you think they measure", Frontiers in Psychology, Vol. 7 No. 1, -932.

Bourdier, L., Morvan, Y., Kotbagi, G., Kern, L., Romo, L. and Berthoz, S. (2018), "Examination of emotion-induced changes in eating: a latent profile analysis of the emotional appetite questionnaire", Appetite, Vol. 123, pp. 72-81.

Camilleri, G.M., Méjean, C., Kesse-Guyot, E., Andreeva, V.A., Bellisle, F., Hercberg, S., Burton, P., Smit, H.J. and Lighowler, H.J. (2007), "The influence of restrained and external eating patterns on overeating", Appetite, Vol. 49, pp. 191-197.

Cardi, V., Leppanen, J. and Treasure, J. (2015), "The effects of negative and positive mood induction on eating behaviour: a meta-analysis of laboratory studies in the healthy population and eating and weight disorders", Neuroscience and Biobehavioral Reviews, Vol. 57, pp. 299-309.

Carlson, R.V., Boyd, K.M. and Webb, D.J. (2004), "The declaration of Helsinki's international guidelines for research ethics: past, present and future", British Journal of Chinical Pharmacology, Vol. 55, pp. 421-422.

Chao, A., Grilo, C.M., White, M.A. and Sinha, R. (2015), "Food cravings mediate the relationship between chronic stress and body mass index", Journal of Health Psychology, Vol. 20 No. 6, pp. 721-729.

Frayn, M. and Knäuper, B. (2018), "Emotional eating and weight in adults: a review", Current Psychology, Vol. 37 No. 4, pp. 924-933.

French, S.A., Epstein, L.H., Jeffery, R.W., Blundell, J.E. and Wardle, J. (2012), "Eating behavior dimensions. Associations with energy intake and body weight. A review", Appetite, Vol. 59 No. 2, pp. 541-549.

Hays, N.P. and Roberts, S.B. (2008), “Aspects of eating behaviors 'disinhibition' and 'restraint' are related to weight gain and BMI in women", Obesity, Vol. 16 No. 1, pp. 52-58.

Hill, J.O., Wyatt, H.R. and Peters, J.C. "The importance of energy balance”, European Endocrinology, Vol. 9 No. 2, p. 111.

Iacovino, J.M., Gredysa, D.M., Altman, M. and Wilfley, D.E. (2012), "Psychological treatments for binge eating disorder", Current Psychiatry Reports, Vol. 14 No. 4, pp. 432-446.

Imperatori, C., Innamorati, M., Tamburello, S., Continisio, M., Contardi, A., Tamburello, A. and Fabbricatore, M. (2013), "Gender differences in food craving among overweight and obese patients attending low energy diet therapy: a matched case-control study", Eating and Weight Disorders - Studies on Anorexia, Bulimia and Obesity, Vol. 18 No. 3, pp. 297-303.

Konttinen, H., van Strien, T., Männistö, S., Jousilahti, P. and Haukkala, A. (2019), "Depression, emotional eating and long-term weight changes: a population-based prospective study", International Journal of Behavioral Nutrition and Physical Activity, Vol. 16 No. 1, pp. 1-11.

Liu, C.M. and Kanoski, S.E. (2018), "Homeostatic and non-homeostatic controls of feeding behavior: distinct vs. common neural systems", Physiology and Behavior, Vol. 193, pp. 223-231.

Lluch, A., Herbeth, B., Mejean, L. and Siest, G. (2000), "Dietary intakes, eating style and overweight in the Stanislas Family Study", International Journal of Obesity, Vol. 24 No. 11, pp. 1493-1499.

Mason, T.B. and Lewis, R.J. (2014), "Profiles of binge eating: the interaction of depressive symptoms, eating styles, and body mass index", Eating Disorders, Vol. 22 No. 5, pp. 450-460.

Nightingale, B.A. and Cassin, S.E. (2019), "Disordered eating among individuals with excess weight: a review of recent research”, Current Obesity Reports, Vol. 8 No. 2, pp. 112-127.

O'Connor, D.B., Jones, F., Conner, M., McMillan, B. and Ferguson, E. (2008), "Effects of daily hassles and eating style on eating behavior”, Health Psychol, Vol. 27, pp. 20-31. 
NFS

52,1

Péneau, S., Menard, E., Mejean, C., Bellisle, F. and Hercberg, S. (2013), "Sex and dieting modify the association between emotional eating and weight status", The American journal of clinical nutrition, Vol. 97 No. 6, pp. 1307-1313.

Pinaquy, S., Chabrol, H., Simon, C., Louvet, J.P. and Barbe, P. (2003), "Emotional eating, alexithymia, and binge-eating disorder in obese women", Obesity Research, Vol. 11 No. 2, pp. 195-201.

Scherwitz, L. and Kesten, D. (2005), "Seven eating styles linked to overeating, overweight, and obesity", Explore, Vol. 1 No. 5, pp. 342-359.

Schulz, S. and Laessle, R.G. (2010), "Associations of negative affect and eating behaviour in obese women with and without binge eating disorder", Eating and Weight Disorders-Studies on Anorexia, Bulimia and Obesity, Vol. 15, pp. 287-293.

Stice, E., Presnell, K. and Spangler, D. (2002), "Risk factors for binge eating onset in adolescent girls: a 2-year prospective investigation”, Health Psychology, 2002, Vol. 21 No. 2, pp. 131-138.

Treasure, J., Claudino, A.M. and Zucker, N. (2010), Eating disorders. Lancet, Vol. 375, pp. 583-593.

Udo, T. and Grilo, C.M. (2018), "Prevalence and correlates of DSM-5-defined eating disorders in a nationally representative sample of US adults", Biological Psychiatry, Vol. 84 No. 5, pp. 345-354.

Vainik, U., García-García, I. and Dagher, A. (2019), "Uncontrolled eating: a unifying heritable trait linked with obesity, overeating, personality and the brain", European Journal of Neuroscience, Vol. 50 No. 3, pp. 2430-2445.

Van Strien, T. (2018), "Causes of emotional eating and matched treatment of obesity", Current Diabetes Reports, Vol. 18 No. 6, pp. 1-8.

Van Strien, T., Frijters, J.E., Bergers, G.P. and Defares, P.B. (1986), "The Dutch eating behavior questionnaire (DEBQ) for assessment of restrained, emotional, and external eating behavior", International Journal of Eating Disorders, Vol. 5 No. 2, pp. 295-315.

World Health Organization (WHO) (2020), "Obesity and overweight”, available online: www.who.int/ news-room/fact-sheets/detail/obesity-and-overweight (accessed 7 September 2020).

Yu, Z., Indelicato, N.A., Fuglestad, P., Tan, M., Bane, L. and Stice, C. (2018), "Sex differences in disordered eating and food addiction among college students", Appetite, Vol. 129, pp. $12-18$.

\section{Further reading}

Péneau, S. (2014), "The associations between emotional eating and consumption of energy-dense snack foods are modified by sex and depressive symptomatology", The Journal of Nutrition, Vol. 144 No. 8, pp. 1264-1273.

\section{Corresponding author}

Maša Cernelič-Bizjak can be contacted at: Masa.Cernelic@fvz.upr.si

For instructions on how to order reprints of this article, please visit our website: 